Carla Ghizzoni, Cultura magistrale nella Lombardia del primo Novecento. Il contributo di Maria agnocavallo (1869-1956)

Brescia, La Scuola Editrice, coll. « Collana Paedagogica », 2005, 505 p.

Michel Ostenc

URL : http://journals.openedition.org/assr/6302

DOI : 10.4000/assr.6302

ISSN : $1777-5825$

Éditeur

Éditions de l'EHESS

Édition imprimée

Date de publication : 1 juin 2007

Pagination : $97-251$

ISBN : 978-2-7132-2143-9

ISSN : 0335-5985

Référence électronique

Michel Ostenc, « Carla Ghizzoni, Cultura magistrale nella Lombardia del primo Novecento. I/ contributo di Maria agnocavallo (1869-1956) », Archives de sciences sociales des religions [En ligne], 138 | avril - juin 2007, document 138-45, mis en ligne le 12 septembre 2007, consulté le 21 septembre 2020. URL : http://journals.openedition.org/assr/6302 ; DOI : https://doi.org/10.4000/assr.6302 


\section{Carla Ghizzoni, Cultura magistrale nella Lombardia del primo Novecento. Il contributo di Maria agnocavallo (1869-1956)}

Brescia, La Scuola Editrice, coll. « Collana Paedagogica », 2005, 505 p.

\section{Michel Ostenc}

1 La maîtresse d'école a été longtemps négligée par l'histoire de l'éducation et caricaturée par la littérature italienne. Son rôle social fut pourtant des plus importants dans la péninsule à la fin du xix et au début du $\mathrm{xx}^{\mathrm{e}}$ siècle. Carla Ghizzoni avait déjà attiré l'attention des spécialistes sur le cas de Maria Magnocavallo au colloque de Brescia, organisé en 1993 pour commémorer le centenaire de la revue Scuola Italiana Moderna (« Dall'aula alla redazione. Il contributo di Maria Magnocavallo», in Mario Cattaneo, Luciano Pazzaglia (éds.), Maestri, educazione popolare e società in «Scuola Italiana Moderna (1893-1993)», Brescia, La Scuola Ed., 1997, pp. 347-387). Cette institutrice exerça de 1890 à 1928 les fonctions de directrice didactique qui correspondent à peu près à celles d'une inspectrice primaire en France. Elle joua un rôle très actif dans les organisations catholiques milanaises avant de figurer parmi les fondatrices de l'association d'enseignants "Nicolò Tommaseo" dont elle assura la présidence jusqu'à sa dissolution par le régime fasciste en 1930. Les activités pédagogiques et sociales de Maria Magnocavallo s'insérèrent d'abord dans celles des sœurs du Cénacle. Cette congrégation française, installée à Milan depuis 1882, avait pour aumônier Achille Ratti, le futur pape Pie XI. Il s'agissait de promouvoir une nouvelle conception éminemment sociale du sacerdoce de l'enseignant; mais les associations catholiques entendaient aussi neutraliser les tendances anticléricales qui se multipliaient dans l'enseignement primaire à l'instigation des municipalités démocrates milanaises de la fin du xix ${ }^{e}$ siècle. Cette expérience permit l'émergence dans les milieux catholiques lombards d'une vocation professionnelle enseignante qui caractérisera plus tard le pontificat de Pie XI, et la prise de conscience de la nécessité 
d'une confrontation avec l'anticléricalisme dans le cadre des institutions de l'État italien. Maria Magnocavallo participa aussi aux activités du cercle «Luigi Rossari » qui proposait, après les tragiques événements de 1898 , une réflexion politique et sociale sur le rôle des classes dirigeantes et sur la participation populaire à la vie publique ; mais elle était surtout préoccupée par l'émancipation féminine et par le vote des femmes qui furent l'objet de nombreux débats au sein de l'Union des « Donne Cattoliche d'Italia ».

2 L'association «Nicolò Tommaseo " multiplia les initiatives en vue du maintien de l'enseignement de la religion à l'école primaire et Maria Magnocavallo lutta pour le respect des droits des institutrices lorsque la loi Credaro de 1911 fit passer l'enseignement élémentaire de la responsabilité des communes à celle de l'État ; mais au-delà de son engagement pour la défense des valeurs chrétiennes, la directrice didactique restait très attachée à l'unité du monde enseignant, péniblement acquise au début du xxe siècle au sein de l'Union Magistrale Nationale. Maria Magnocavallo anima pendant quarante ans (1916-1956) la section didactique de Scuola Italiana Moderna. Cette revue pédagogique était née à l'initiative d'un groupe de catholiques de Brescia qui associait la prédication d'Achille Ratti à une conception de l'enseignement fortement inspirée du spiritualisme des pédagogues neo-guelfes italiens du XIX siècle (Rosmini, Tommaseo ou Lambruschini). Au lendemain de la Grande Guerre, le thème national rapprocha le "popularisme» catholique de l'«idéalisme populaire » du pédagogue Giuseppe Lombardo-Radice. La pédagogie de Maria Magnocavallo semblait suivre la réaction conservatrice de la culture italienne de l'époque en privilégiant la formation d'un « homme fort "; mais elle se distinguait des recommandations viriles et guerrières du fascisme en concevant cette force d'âme comme la capacité de rester fidèle à ses convictions religieuses. En cela, elle était proche de la spiritualité des intellectuels catholiques et des ecclésiastiques de Brescia, comme Mario Bendiscioli et Giambattista Montini, le futur pape Paul VI. La direction de Scuola Italiana Moderna confia d'ailleurs au pédagogue Mario Casotti le soin de formuler une théorie moderne d'éducation, soulignant sa spécificité chrétienne dans l'Italie concordataire. Carla Ghizzoni avait déjà abordé les problèmes de l'éducation dans l'Italie des années 1920 à travers une étude fort remarquée de la revue des Jésuites Civiltà cattolica ("Educazione e scuola laica all'indomani della Grande guerra. Il contributo de "La Civiltà cattolica" (1918-1931) », Brescia, La Scuola Ed., 1997 ; Voir le compte rendu en français de Ester De Fort, dans Poedagogica historica, XXXIV-3, 1998, pp. 878-880).

3 Son ouvrage sur Maria Magnocavallo n'est pas seulement la biographie d'une personnalité discrète, mais aussi forte que déterminée. L'existence du personnage est en effet profondément immergée dans un contexte social et culturel. Elle contribue à faire d'un livre solidement construit à partir d'archives encore inexploitées une véritable fresque de la culture enseignante lombarde de la première moitié $d u x^{e}$ siècle ; mais elle nous révèle aussi l'inlassable activité d'une militante féministe tournée vers l'éducation et la culture des milieux populaires. 